\title{
The Determination of Phosphorus and Nitrogen in Plankton.
}

\author{
By \\ L. H. N. Cooper, Ph.D., A.I.C., \\ Assistant Chemist at the Plymouth Laboratory.
}

DURING the course of an investigation on the seasonal changes in phytoplankton (Harvey, 1934), the need arose for analyses of organic phosphorus. The quantities available being very small it was necessary to develop a method of analysis.

Since the plankton consists of many different organisms ranging widely in size and shape and organic content, neither a description of its composition, its volume, nor its wet or dry weight gives a clear indication of its value as food for other animals. It was considered that its phosphorus or nitrogen content, as indicative of protein content, would best serve this purpose and allow comparison to be made between different samples of plankton.

\section{Determination of Total Phosphorus in Plankton.}

The method of Juday, Birge, Kemmerer, and Robinson for total phosphorus in lake residues as modified by Robinson and Kemmerer (1930) and Titus and Meloche (1931), in which the plankton sample was digested with a mixture of sulphuric, hydrochloric, and nitric acids, was not satisfactory for marine plankton. It proved very difficult to drive off the last of the oxidising agent; which interfered with the subsequent reduction of the phosphomolybdate by stannous chloride. Various modifications of the nitric acid oxidation as well as a number of ignition methods were tried with only partial success. Finally perhydrol (Merck's $30 \%$ hydrogen peroxide) in presence of sulphuric acid was found to be the most suitable oxidising agent. For the determination of total phosphorus in sea-water Kreps and Osadchih (1933) used 3\% hydrogen peroxide in order to oxidise and hydrolyse the organic matter, and Kalle (1933) for the same purpose used potassium persulphate whose action is essentially the same. Perhydrol has obvious advantages over weaker solutions of hydrogen peroxide. But, when the product of digestion was diluted to $100 \mathrm{ml}$. and treated with the usual molybdimetric reagents, the colour developed was invariably off shade. Furthermore, halogens 
set free by the oxidation of sea salts were only driven off completely when attention had been given to the design of an air bath which would enable the fumes to escape from the flask without collecting on its upper walls and running back. The following procedure has proved highly satisfactory.

Method. A suitable volume of the plankton concentrated in a small volume of sea-water, as obtained in the bucket of a tow-net, was filtered through a small disc of bolting silk (200 mesh to the linear inch ; Harvey, this Journal, pp. 770). The first 20-25 ml. of filtrate was again passed through the filter, since it was found to contain some of the smaller plankton organisms. The final filtrate, which was usually clear to the eye, was transferred to a small wash-bottle and used for washing down the sides of the funnel. The filter disc was removed from the funnel and the plankton washed into a $50 \mathrm{ml}$. Erlenmeyer flask with a jet of distilled water amounting to about 5-10 ml. in all. Concentrated sulphuric acid $(0.2 \mathrm{ml}$.) was added and the liquid was evaporated without boiling during the course of one hour in a covered air bath at $115-120^{\circ}$, and subsequently slowly raised to $160^{\circ}$.

The carbonaceous residue in the flask at $150-160^{\circ}$ was treated with Merck's perhydrol, drop by drop. By twirling the flask the perhydrol can be readily spread over the bottom of the flask before decomposing and three to five drops usually sufficed to oxidise the carbonaceous matter. It was found better to re-heat between successive additions of perhydrol. Occasionally the residue remained brown and in such a case it was taken up with $5 \mathrm{ml}$. of water, re-evaporated, and again treated with perhydrol. Five drops of perhydrol contained only $0 \cdot 1 \gamma \mathrm{P}_{2} \mathrm{O}_{5}$ which could be safely ignored.* Finally the flask was heated for twenty minutes at $180^{\circ}$. After cooling, about $8 \mathrm{ml}$. of distilled water was added and the solution allowed to simmer gently while the volume fell to about $4 \mathrm{ml}$. This treatment should have destroyed any persulphate which had survived heating at $180^{\circ}$. It is doubtful if it was of any value, as is sometimes claimed, in hydrolysing to orthophosphate any pyrophosphate which might have been formed [cf. Berthelot and André (1896)]. The good agreement between duplicate determinations and the recovery from trial runs with known amounts of phosphate showed that pyrophosphate was not formed. This agrees with the findings of Titus and Meloche (1931).

In order to remove silica, the acid solution was transferred to a calibrated $10 \mathrm{ml}$. pointed centrifuge tube and the Erlenmeyer flask washed out with 2-3 ml. of water in all. The acid solutions and washings were thoroughly mixed by a glass rod, their volume noted and centrifuged. Then $5 \mathrm{ml}$. of the supernatant liquor was pipetted off and made up to $100 \mathrm{ml}$. Aliquot parts of this were again diluted to $100 \mathrm{ml}$. and then 
compared in Hehner cylinders in duplicate with a standard containing, say, $12.5 \gamma \mathrm{P}_{2} \mathrm{O}_{5}$ per $100 \mathrm{ml} *$ (=-125 $\mathrm{mg} . \mathrm{P}_{2} \mathrm{O}_{5}$ per cubic metre).

By this double dilution four advantages were gained: $(a)$ the foreign matter which earlier upset the colour match was rendered innocuous, (b) when adding the acid molybdate reagent it was unnecessary to allow for the small excess of acid already present, $(c)$ the salt error was made negligible, $(d)$ two or more determinations could be made on the same digest. A set of analyses on three sub-samples of one sample of plankton is shown in Table $\mathrm{I}$.

\section{TABLE I.}

Analyses in Triplicate on mixed Plankton filtered from 388 Litres of Water at Station L4, BetweEn the SURFACE AND 45 metres on 12th February, 1934.

Analysed on 13th and 14th February. Sub-samples each compared colorimetrically in duplicate.

Sub sample.

A

B

C
Phosphorus in Plankton expressed as $\gamma \mathrm{P}_{2} \mathrm{O}_{5}$ per cubic metre of sea-water, i.e. as parts per million million.

241

230

246

249

244

245

Mean

The reducing agent consisted of a solution of about $0 \cdot 1 \mathrm{~g}$. of stannous chloride (clear crystals) in $10 \mathrm{ml}$. of concentrated hydrochloric acid. Two drops of this solution were added to the standard or sample under comparison, which was well shaken before and after adding quickly $2.0 \mathrm{ml}$. of the usual $2.5 \%$ solution of ammonium molybdate in $37.5 \%$ (by volume) sulphuric acid. This reversal of the usual order of addition of the two reagents has been found to give more consistent results.

Only one opportunity has presented itself of applying the method, as finally developed, to a catch consisting almost only of plants. The result is shown in Table II, together with a further analysis of a clean sample judged to consist of $70 \%$ to $80 \%$ plants and $30 \%$ to $20 \%$ animals. After making allowance for this, the quantity of organic phosphorus

* $1 \gamma=0.001 \mathrm{mg}$; thus $1 \gamma$ per litre $=1 \mathrm{mg}$. per cubic metre. 
works out in both cases at about $0 \cdot 3 \mathrm{mg} . \mathrm{P}_{2} \mathrm{O}_{5}$ per 1000 " units of plant pigments" (p. 771). This approximate ratio has already found applica-

\section{TABLE II.}

Analyses of Plankton from which the Larger Organisms had BEEN REMOVED.

\begin{tabular}{cccc} 
Date. & \multicolumn{1}{c}{$\begin{array}{c}\text { Description. } \\
\text { Phosphorus expressed } \\
\text { as mg. } \mathrm{P}_{2} \mathrm{O}_{5} \text { per } \\
\text { litre of eatch. }\end{array}$} & $\begin{array}{l}\text { mg. } \mathrm{P}_{2} \mathrm{O}_{5} \text { per } \\
1000 \text { units of } \\
\text { plant pigments" } \\
\text { (p. 771) present. }\end{array}$ \\
$7 / 2 / 34$ & $\begin{array}{c}\text { Almost wholly diatoms } \\
70 \% \text { to } 80 \% \text { diatoms }\end{array}$ & $0 \cdot 089$ & $0 \cdot 31$ \\
& & $1 \cdot 47$ & $0 \cdot 27$ to $0 \cdot 31^{*}$
\end{tabular}

tion (p. 782), and its magnitude has been confirmed by a number of other analyses which have been made in connexion with a research now in progress.

\section{Determination of Total Nitrogen in Plankton.}

The standard micro-Kjeldahl method of Parnas and Wagner, as described by Pregl (1930), has proved excellent. When using $5 \mathrm{ml}$. of $\mathrm{N} / 100$ hydrochloric acid to absorb the ammonia liberated, the amount of nitrogen in the sample needs to be between $0 \cdot 15$ and $0.6 \mathrm{mg}$. Thus about two to three times as much plankton is required as for the phosphorus determination. The plankton sample was washed straight off the silk disc into a micro-Kjeldahl digestion flask and $0 \cdot 2 \mathrm{ml}$. of concentrated sulphuric acid added to avoid loss of nitrogen bases during the evaporation of the water. Most of this was removed by boiling off on the Kjeldahl heating stand and the evaporation completed in an air bath or oven at $120^{\circ}$. The digestion with sulphuric acid $(1 \mathrm{ml}$.$) , mixed potassium and$ copper sulphates and perhydrol, and the distillation and collection of the ammonia in N/100 hydrochloric acid were carried out exactly as described by Pregl. Duplicate runs on a sample of tow-net plankton gave 1.47 and $1.52 \mathrm{mg}$. nitrogen per litre of sample, being $2 \cdot 75$ times the quantity of $\mathrm{P}_{2} \mathrm{O}_{5}$. This ratio is of interest because previous work at Plymouth has shown that the vegetation utilises two and a half times more nitratenitrogen than $\mathrm{P}_{2} \mathrm{O}_{5}$.

In subsequent work time was saved by adding immediately all the sulphuric acid $(1 \mathrm{ml}$.$) and the mixed sulphates to the plankton and$ wash water in the Kjeldahl flask. Evaporation of the water without bumping was assisted by adding occasionally a drop of perhydrol.

* After deducting $30 \%$ to $20 \%$ for phosphorus present in animals. 


\section{SUMMARY.}

Phosphorus in plankton has been determined by digestion with sulphuric acid and perhydrol followed by colorimetric determination.

Nitrogen has been readily determined by the micro-Kjeldahl method of Parnas and Wagner.

\section{REFERENCES.}

Berthelot, and André, G. 1896. Recherches sur l'acide phosphorique : dosage de l'acide pyrophosphorique. Comptes rendus Acad. Sci., Paris, T. 123, pp, 773-776 ; ef. ibid., pp. 776-787.

Harvey, H. W. 1934. Measurement of Phytoplankton P.opulation. Journ. Marine Biol. Assoc., N.S., Vol. XIX, No. 2, pp. 761-773.

Kalle, K. 1933. Phosphat und Gesamtphosphor in Beziehung zu Temperatur, Salzgehalt und Plankton an der Oberfläche der Islandischen Küstengewässer. Ber. der deutsch. Wiss. Komm. f. Meeresforschung, N.F., Bd. 6, pp. 273-299.

Kreps, E., and OsadchiH, M. 1933. The Organic Phosphorus in the Sea. Internat. Revue der gesamt. Hydrobiol. u. Hydrogr., Bd. 29, pp. 221-228.

Pregl, F. 1930. Quantitative Organic Microanalysis. Second English Edition, pp. 109-118. London.

Robinson, R. J., and Kemmerer, G. 1930. Determination of Organic Phosphorus in Lake Waters. Trans. Wisc. Acad. Sci., Vol. 25, pp. 117-121.

Titus, L., and Meloche, V. W. 1931. Note on the Determination of Total Phosphorus in Lake Water Residues. Trans. Wisc. Acad. Sci., Vol. 26, pp. 441-444. 
